\title{
Accessibility as an Impulse Tool for the Gastronomic Zones through the Ordering of Mobility
}

\author{
Diego A. Escobar ${ }^{1 *}$ Santiago Cardona ${ }^{1}$ and Carlos A. Moncada ${ }^{2}$ \\ 'Universidad Nacional de Colombia - Sede Manizales. Facultad de Ingeniería y Arquitectura. Departamento de \\ Ingeniería Civil. Cra 27 \# 64-60, Manizales, 170004, Colombia; scardonau@unal.edu.co; daescobarga@unal.edu.co \\ ¿Universidad Nacional de Colombia - Sede Bogotá. Facultad de Ingeniería. Departamento de Ingeniería Civil y \\ Agrícola. Ciudad Universitaria edificio 214 Oficina 417, Bogotá, 111321, Colombia; camoncada@unal.edu.co
}

\begin{abstract}
Objectives: To evaluate the impact generated in cars travel time by road redirections made in the gastronomic zone in Manizales, Colombia. Methods/Statistical Analysis: Using the global mean accessibility and integral accessibility to gastronomic zone in Manizales for two differents scenarios, before and after the road redirections we will use the saving gradient to measure the impact of the new directions in the urban mobility. Findings: The impact generated by the road redirections in both accessibility measures is negative, so the travel times increase in the new scenario. This would generate a disminution in the use of private vehicule in the gastronomic zone and an increase use for walking and public transport. Application/Improvement: Accessibility as a tool fro urban planning and the measure of the impact of road redirections in specific zones in the cities where it would like to generated a space free of private vehicles.
\end{abstract}

Keywords: Accessibility, Gastronomic Zones, Road Re Direction, Saving Gradient

\section{Introduction}

The impulse of the gastronomic zones, places where a large number of restaurants in a city are concentrated, is a fundamental part to highlight the gastronomic potential of a city, as well as making it more attractive ${ }^{1}$. In this sense, Manizales (Figure 1) capital of the department of Caldas in Colombia, since 2015 has promoted its own gastronomic zone (Zone G), located in the Milan district of the city where more than USD 1.75 million have been invested in urban improvements and developments that include the construction of a boulevard that included the extension of platforms, official parking spaces for vehicles and a lighting improvement $\frac{23.3}{3}$. In 2018, the Mayor of Manizales made the decision to carry out the unification of road directions in Zone $\mathrm{G}$ in order to improve mobility and thus expanding the parking areas due to the fact that there was a strong demand in this sense contrasted with a little supply, which frequently caused parking along platforms and transit lanes, which, being double-direction, impeded enormously the traffic flow ${ }^{4}$. However, this measure had resistance in the resident community of the sector due to the lack of technical studies to support the decision and the actual affectation or benefit for them was not quantified along with the measures taken to mitigate them. Finally, the Mayor of Manizales determined that the unification was going to have a 1-month pilot test (June 5 to July 5,2018 ) where the impact generated by these unifications was measured 5 . Likewise, several technical tables of socialization and impact quantification were to be made with various representatives of the commercial, residential, educational, cult and commercial sectors $\underline{5}$. Finally, this pilot test was extended for 2 more weeks in order to evaluate the impact generated at the time of entering classes of nearby educational institutions. In this research article, we seek to measure the impact generated by road unification in the G Zone of the city in the travel times of the inhabitants by quantifying the gradient of savings

${ }^{*}$ Author for correspondence 

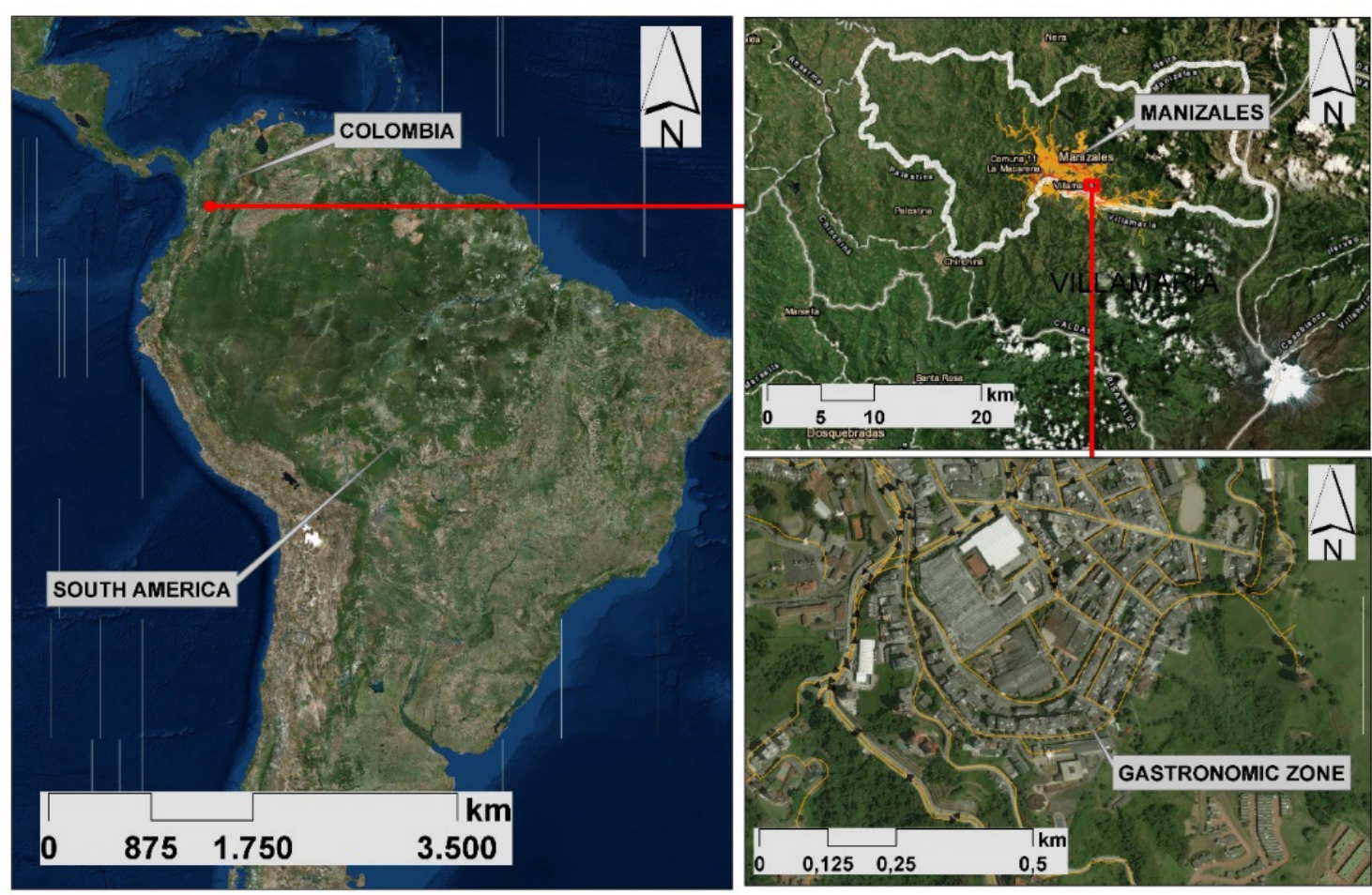

Figure 1. Geographic location of Gastronomic Zone in Manizales.

in global mean accessibility of Manizales and the integral average accessibility of Citizens who wish to access the G Zone on private vehicles.

Accessibility is a transport supply model, which seeks to measure the interaction capacity of individuals or areas of a city towards the different opportunities offered, using a particular mode of transport and with defined impedance variables $\frac{6-8}{}$. This model has had several types of measures that have been developed over the years, among which are measures based on gravity $\underline{\underline{7-9}}$, topological measures ${ }^{10}$, measures of distance or time $e^{11}$ and measures based on utilities $\frac{12}{}$, among others. On the other hand, Ingram (1971) divided the concept of accessibility into two widely known types, the relative accessibility where a measurement is made between two points of the city and the integral accessibility where the accessibility of a set of points with respect to another is measured or vice versa ${ }^{\frac{13}{3}}$. Later, in various investigations the concept of global accessibility has appeared, where a measurement is made between all the nodes and a general analysis of the offer in the city is made through the road infrastructure network in various modes of transport, as public transport, private transport, bicycle or hike, according to the average speed of each of them $\frac{14,15}{}$. The global mean accessibility has been used to evaluate the impact generated by different changes in the road infrastructure network, such as the start-up of new road infrastructure works such as road interchanges ${ }^{\underline{16}}$, tunnels and bridges ${ }^{\underline{ }}$ and even the evaluation of road re-routes $\frac{18,19}{}$. Likewise, accessibility has been used as an urban planning method ${ }^{20}$, public transport planning 21 , and studies on social exclusion $\frac{22}{2}$, metropoli$\tan$ areas analysis $\frac{23,24}{}$, access to libraries ${ }^{25}$, national parks $s^{26}$ and jobs $\underline{\underline{6}}$, among many others.

Following the introduction, the research method is explained, results are shown and discussed, and finally study conclusions are established.

\section{Methodology}

Regarding the methodology used in the investigation, which can be seen in Figure 2, it is observed that there are four stages, including a stage of data collection necessary to perform the calculations and analysis.

\subsection{Road Network and Neighborhood Polygon}

The road infrastructure network for the study area is obtained through previous research $\frac{14,16,17}{17}$, which have the latest inaugurated road infrastructure works, also 


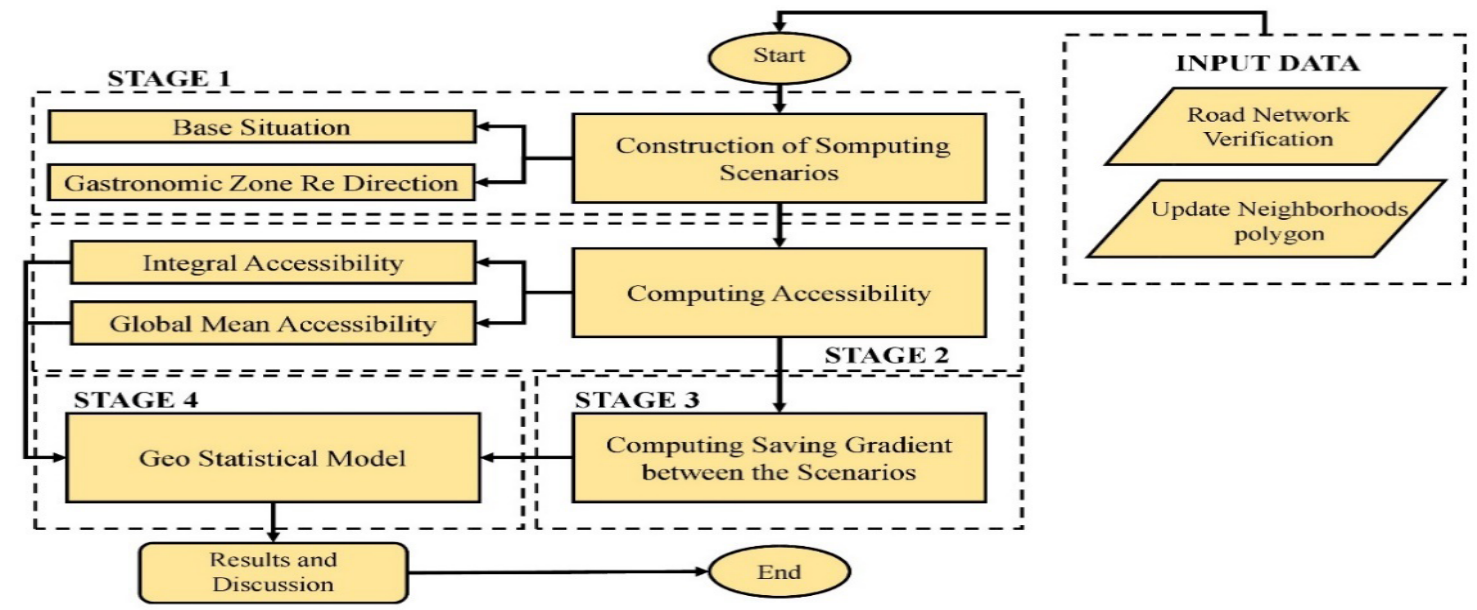

Figure 2. Methodology for investigation.

have the necessary conditions to perform the subsequent calculations, among which are listed to comply with the theory of graphs that includes the construction of the network through nodes and $\operatorname{arcs}^{27}$, the speeds of the arcs of the network through Global Positioning Tools (GPS) $\underline{28}$ and the calculation of arc travel lengths and times using Geographical Information System (GIS) tools. On the other hand, it is necessary to take the neighborhood polygon of Manizales, which was built with the help of GIS tools for previous research $\frac{14-17}{}$ and update the data corresponding to the population for 2017 through the population projections indicated by the National Administrative Department of Statistics (DANE for its acronym in spanish $\underline{29}$.

\subsection{Scenarios Construction}

In this research, two proposed scenarios will be taken into account; the first one corresponds to the accessibility calculations with the addresses presented by the road infrastructure network before the direction changes in Zone $\mathrm{G}$, called base situation. The second scenario corresponds to the calculation of accessibility including the changes of address present in the study area, called redirections gastronomic zone $e^{4}$.

\subsection{Global Mean Accessibility Calculation}

On this stage, we proceed to calculate the global mean accessibility and integral accessibility for both scenarios.
Next, the calculation methodology for each of them will be described.

Global Mean Accessibility, as previously stated, the calculation of the global mean accessibility is an average of the trips among all the nodes of the road network, so the vector of average Travel time (Tv) must be obtained. First, we obtain the matrix of travel times among all the nodes of the network, using TRANSCAD 7.0, GIS software specialized in transport models, which has a tool that uses the Dijkstra algorithm of minimum paths to find the best possible route among all the nodes of the network and thus compute the travel time matrix ${ }^{30}$. Then, from the matrix of travel times, the addition of times for each node is made and divided by the nodes to which they traveled in the modeling, obtaining the vector of average time of travel which is the necessary input for the construction of the isochronous accessibility curves, using the geo-statistical model $\frac{14,16-17}{}$.

For the integral accessibility calculation, the nodes corresponding to Zone G must be defined. After that, the calculation of the travel time matrix of all the nodes of the road network to the target nodes carried out in the same way as it was made in the global mean accessibility, using the software TRANSCAD 7.0 and the algorithm of minimum paths of Dijkstra ${ }^{30}$. Finally, the vector of integral accessibility times is obtained, making the summation of the times of each node and dividing them by the objective nodes ${ }^{31}$. This vector will be used to compute the geo-statistical model and obtain the isochronic curves of integral accessibility. 


\subsection{Saving Gradient}

The calculation of the savings gradient is used to compare two accessibility scenarios, in this case the global mean accessibility and integral accessibility of the base scenario and the redirection of the G Zone. For this, the travel time vectors obtained in the previous stage and the savings gradient is calculated as in previous investigations $\frac{14,16,17}{}$. We find a percentage vector of savings in travel times that help us to perform the geo-statistical model and thus determine which areas were affected by the measures taken in terms of direction in Zone $\mathrm{G}^{16,17,32}$.

\subsection{Geo Statistical Model}

With the travel time vectors of the global and integral average accessibility and the saving gradient vector, we proceed to use the ordinary Kriging geo-statistical model with a semi-linear variogram to obtain the isochronous curves $^{33}$. This model has been used over the years as a predictor model in transport models $\frac{16,17,32}{}$.

\section{Results and Discussion}

\subsection{Delimitation of Gastronomic Zone and Road Network Re-direction}

Figure 1 shows the geolocation of Zone G in the city of Manizales, also for the calculation of the future scenario in global mean accessibility and integral accessibility, the nodes of the road infrastructure network that are part of the gastronomic area should be delimited and make the changes of directions adopted by the Mayority of Manizales ${ }^{4}$. In part B of Figure 3, the current direction of Zone $\mathrm{G}$ is observed which corresponds to the calculation base scenario. In part A of Figure 3 is the network of road infrastructure with the changes of direction suggested and made by the Mayor's Office of Manizales, where fundamentally the 3-way senses on the study area were unified, generating the flow to make a move counterclockwise to enter and exit the area.

\subsection{Global Mean Accessibility and its Saving Gradient}

Figure 4 shows the isochrone curves of global mean accessibility for the base scenario (left part) and for the scenario with the re direction of Zone G (right part), where the minimum and maximum time recorded for the average

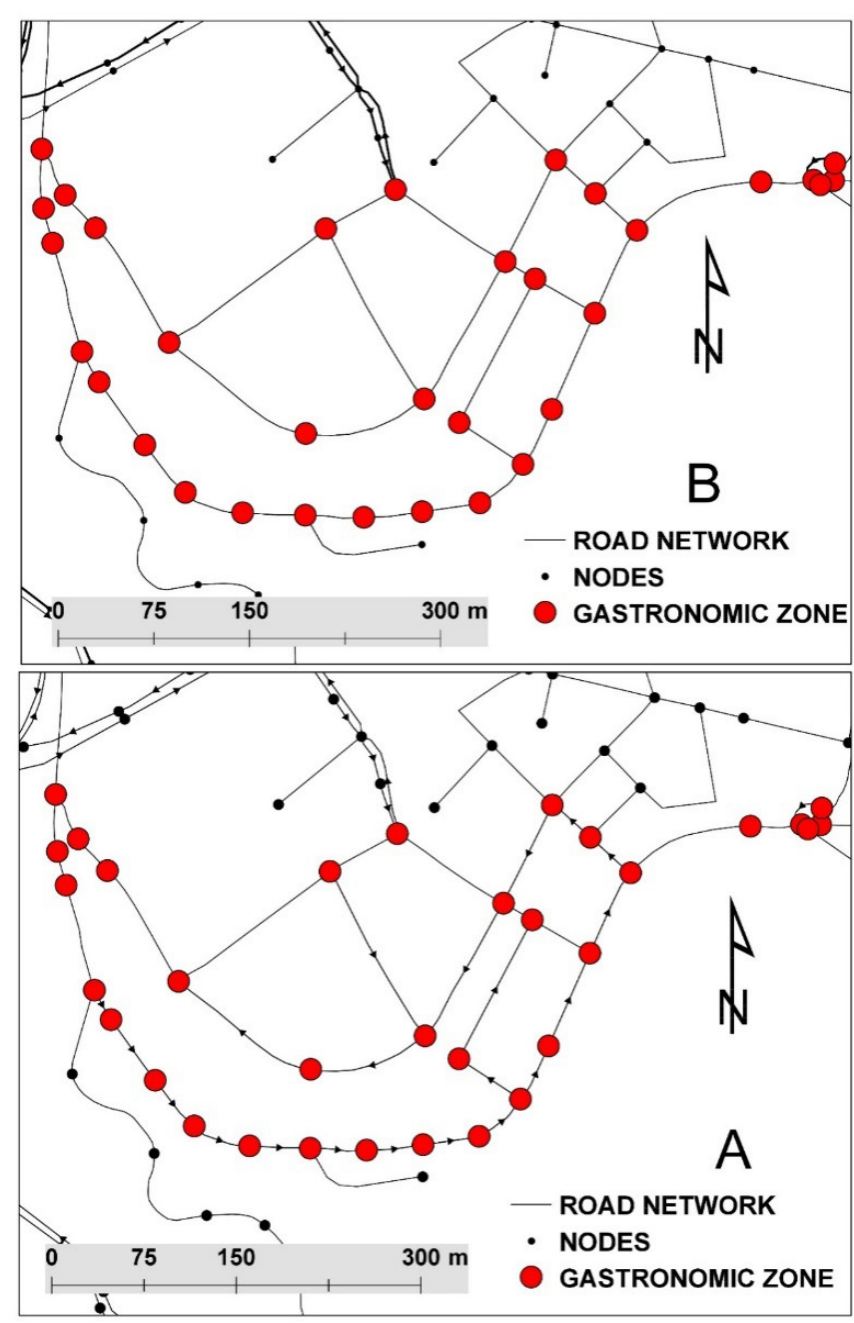

Figure 3. Road infrastructure network A) Base Situation and B) Gastronomic Zone re direction.

times of trip is equal with 16.59 minutes and 52.11 minutes respectively so both scenarios are similar in this regard. In addition, in the box where an approach to the study area is made, a small change is observed in the isochronous curves, where the isochronous curve between 16.59 minutes and 20 minutes decreases its influence zone in the re-directing scenario of the Zone. G, since the isochronous curve between 20 and 25 minutes grew.

The analysis of coverage and population for both scenarios of the isochrone curves of global mean accessibility is shown in Table 1. There, it is observed how the coverage of population and area for the isochronous curve between 16.59 and 20 minutes' decreases by $0.13 \%$ ( 557 inhabitants and 8 ha) between the base scenario and the re-directing scenario of the gastronomic zone, adding to the coverage of the next isochronous curve. In the other isochronous 

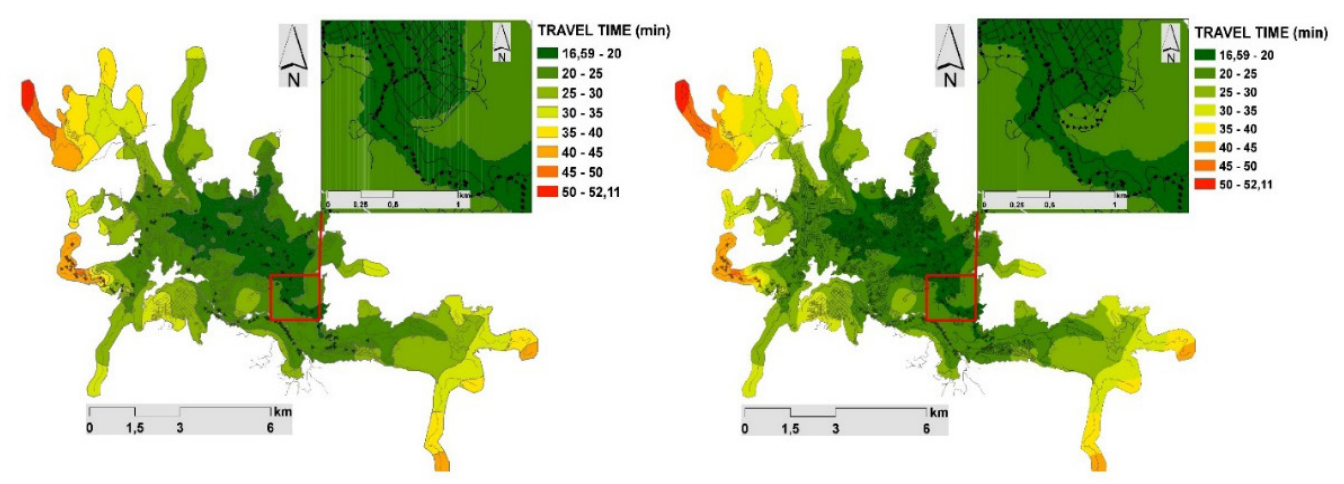

Figure 4. Isochrones curves, global mean accessibility.

curves, it did not appear a significant difference. Finally, it should be noted that $1,00 \%$ of the population is covered for a maximum time of up to 45 minutes, which indicates that the population density of the city is concentrated in an area smaller than its potential and there are analyzed polygons with low volume of inhabitants, since they correspond to the peripheral parts of exit to other cities and zones of expansion $\underline{28}$.

Table 1. Area and inhabitants coverage per isochrones curve, global mean accessibility

\begin{tabular}{|c|c|c|c|c|c|c|}
\hline \multicolumn{7}{|c|}{ Global Average Accesibility - Base Situation } \\
\hline $\begin{array}{l}\text { Isochronos } \\
\text { Curve }\end{array}$ & Area & Inhabitants & $\%$ Area & $\%$ Inhabitants & $\begin{array}{l}\% \text { Accumulated } \\
\text { Area }\end{array}$ & $\begin{array}{l}\% \text { Accumulated } \\
\text { Inhabitants }\end{array}$ \\
\hline $16,59-20$ & 876,51 & 134081,83 & $14,95 \%$ & $31,95 \%$ & $14,95 \%$ & $31,95 \%$ \\
\hline $20-25$ & 2091,29 & 209225,44 & $35,67 \%$ & $49,85 \%$ & $50,61 \%$ & $81,80 \%$ \\
\hline $25-30$ & 1389,99 & 57039,11 & $23,71 \%$ & $13,59 \%$ & $74,32 \%$ & $95,39 \%$ \\
\hline $30-35$ & 746,14 & 15298,88 & $12,72 \%$ & $3,65 \%$ & $87,04 \%$ & $99,04 \%$ \\
\hline $35-40$ & 406,17 & 2960,65 & $6,93 \%$ & $0,71 \%$ & $93,97 \%$ & $99,74 \%$ \\
\hline $40-45$ & 258,14 & 1080,92 & $4,40 \%$ & $0,26 \%$ & $98,37 \%$ & $100,00 \%$ \\
\hline $45-50$ & 57,30 & 0,00 & $0,98 \%$ & $0,00 \%$ & $99,35 \%$ & $100,00 \%$ \\
\hline $50-52,11$ & 38,10 & 0,00 & $0,65 \%$ & $0,00 \%$ & $100,00 \%$ & $100,00 \%$ \\
\hline Totally & 5863,63 & 419686,84 & $100 \%$ & $100 \%$ & & \\
\hline \multicolumn{7}{|c|}{ Global Average Accesibility - Gastronomic Zone Re Direction Scenario } \\
\hline $\begin{array}{l}\text { Isochronos } \\
\text { Curve }\end{array}$ & Area & Inhabitants & $\%$ Area & $\%$ Inhabitants & $\begin{array}{l}\% \text { Accumulated } \\
\text { Area }\end{array}$ & $\begin{array}{l}\% \text { Accumulated } \\
\text { Inhabitants }\end{array}$ \\
\hline $16,59-20$ & 868,26 & 133484,54 & $14,81 \%$ & $31,81 \%$ & $14,81 \%$ & $31,81 \%$ \\
\hline $20-25$ & 2099,33 & 209782,03 & $35,80 \%$ & $49,99 \%$ & $50,61 \%$ & $81,79 \%$ \\
\hline $25-30$ & 1390,04 & 57079,72 & $23,71 \%$ & $13,60 \%$ & $74,32 \%$ & $95,39 \%$ \\
\hline $30-35$ & 746,20 & 15298,94 & $12,73 \%$ & $3,65 \%$ & $87,04 \%$ & $99,04 \%$ \\
\hline $35-40$ & 406,28 & 2960,55 & $6,93 \%$ & $0,71 \%$ & $93,97 \%$ & $99,74 \%$ \\
\hline $40-45$ & 258,13 & 1081,04 & $4,40 \%$ & $0,26 \%$ & $98,37 \%$ & $100,00 \%$ \\
\hline $45-50$ & 57,30 & 0,00 & $0,98 \%$ & $0,00 \%$ & $99,35 \%$ & $100,00 \%$ \\
\hline $50-52,11$ & 38,10 & 0,00 & $0,65 \%$ & $0,00 \%$ & $100,00 \%$ & $100,00 \%$ \\
\hline Totally & 5863,63 & 419686,80 & $100 \%$ & $100 \%$ & & \\
\hline
\end{tabular}




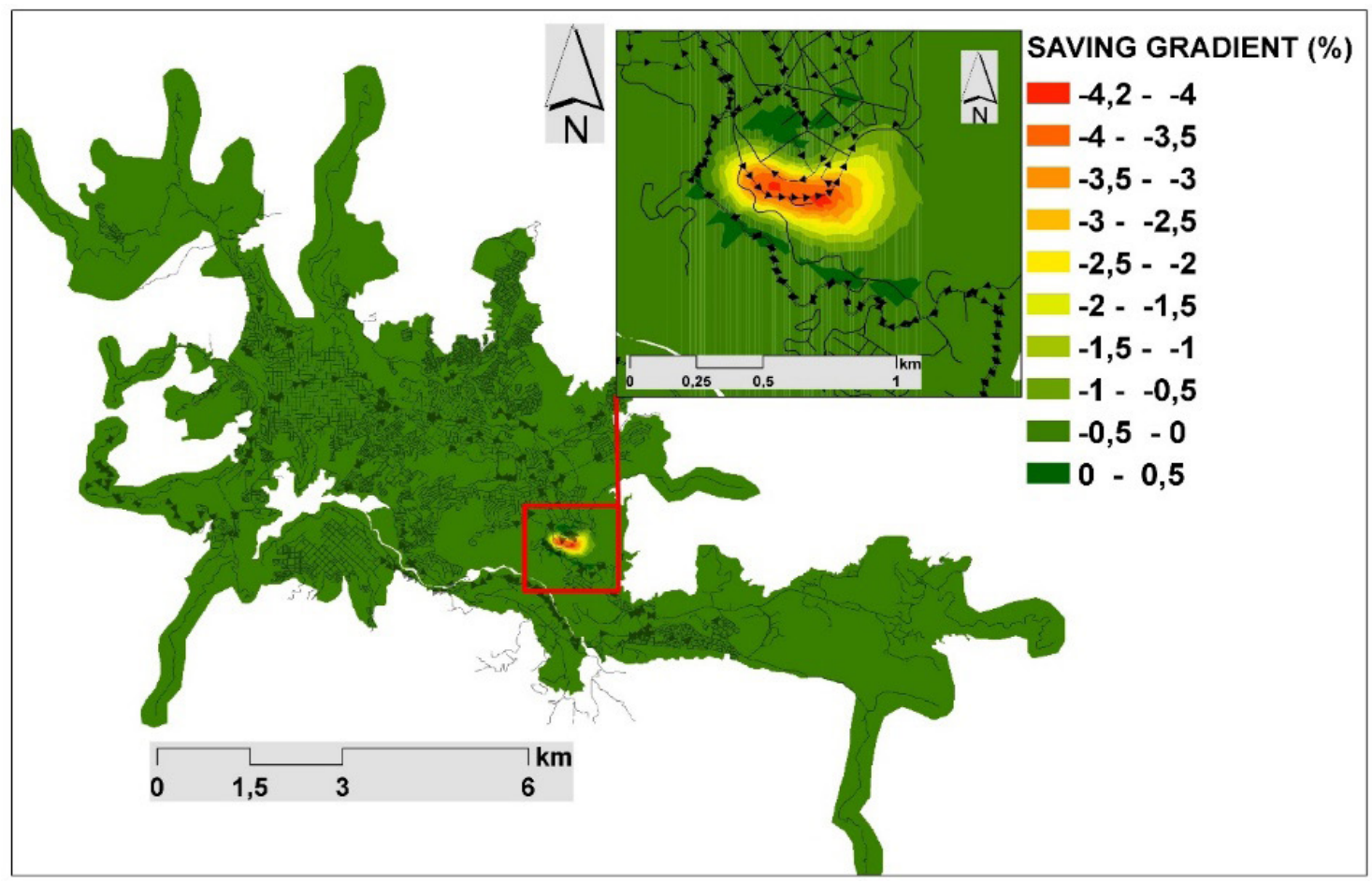

Figure 5. Saving Gradient, global mean accessibility.

On the other hand, Figure 5 shows the savings gradient that analyzes the difference in travel times given in the global mean accessibility of both scenarios studied. In this, differences are observed in the average travel times of up to $-4.2 \%$, concentrated near the study area, where even benefits of up to $0.5 \%$ are observed. Most of the city is covered by differences between $-0.5 \%$ and $0 \%$, which indicates that at the level of global mean accessibility there is no large impact on mobility, the greatest differences are seen in the box, which corresponds to the study area.

Table 2 shows the population and area coverage for the isochronous curves of the comparison savings gradient among the global mean accessibility scenarios studied. According to this, $0.38 \%$ of the population, 1,601 inhabitants and $0.44 \%$ of the area, 26 ha, are covered by savings gradients between $-4.2 \%$ and $-0.5 \% .99 .43 \%$ of the population (417,406 inhabitants) and $99.43 \%$ of the area (5830 ha) are on the gradient between $-0.5 \%$ and $0 \%$, which indicates the few differences generated in terms of average time of trip between both scenarios. Finally, for $0.1593 \%$ of the population (669 inhabitants) and $0.1344 \%$ ( $8 \mathrm{ha}$ ) there is a saving of up to $0.5 \%$ through re-direction in the gastronomic zone.
Table 2. Area and inhabitants coverage per isochrones curve, saving gradient between global mean accessibility on analyzed scenarios

\begin{tabular}{|c|c|c|c|c|}
\hline \multicolumn{5}{|c|}{ Saving Gradient - Base Scenario } \\
\hline $\begin{array}{l}\text { Isochrones } \\
\text { Curve }\end{array}$ & Area & Inhabitants & $\%$ Area & $\begin{array}{l}\% \\
\text { Inhabitants }\end{array}$ \\
\hline$-4,2--4$ & 0,421 & 24,096 & $0,0072 \%$ & $0,0057 \%$ \\
\hline$-4--3,5$ & 2,441 & 140,573 & $0,0416 \%$ & $0,0335 \%$ \\
\hline$-3,5--3$ & 2,186 & 133,862 & $0,0373 \%$ & $0,0319 \%$ \\
\hline$-3--2,5$ & 2,213 & 141,984 & $0,0377 \%$ & $0,0338 \%$ \\
\hline$-2,5--2$ & 2,775 & 176,700 & $0,0473 \%$ & $0,0421 \%$ \\
\hline$-2--1,5$ & 3,586 & 227,943 & $0,0612 \%$ & $0,0543 \%$ \\
\hline$-1,5--1$ & 4,430 & 282,406 & $0,0755 \%$ & $0,0673 \%$ \\
\hline$-1--0,5$ & 7,464 & 473,935 & $0,1273 \%$ & $0,1129 \%$ \\
\hline$-0,5-0$ & 5830,340 & 417406,535 & $99,4304 \%$ & $99,4591 \%$ \\
\hline $0-0,5$ & 7,882 & 668,508 & $0,1344 \%$ & $0,1593 \%$ \\
\hline Totally & 5863,738 & 419676,541 & $100,0 \%$ & $100,0 \%$ \\
\hline
\end{tabular}

\subsection{Integral Accessibility and its Saving}

\section{Gradient}

Regarding the integral accessibility result for the studied scenarios, the isochronous curves can be observed 
in Figure 6 where there is a minimum travel time to the nodes of the study area of 1.61 minutes in the baseline scenario, while for the scenario corresponding to the redirecting of Zone $\mathrm{G}$, this data increases to 2.43 minutes, explained by the decrease in route alternatives caused by the change of the directions in the arcs, where it passes from bi direction roads to one direction in the studied area. As for the maximum times, which are in the west areas of the city, the difference in time is minimal with only 0.06 minutes. In addition, in the box can be seen the change in the size of the isochronous curves, where the coverage of the first interval of the isochronous curves decreases in the re-direction scenario, increasing the coverage of the following time intervals.
On Table 3, the coverage analysis of the isochronic accessibility curves for both scenarios can be observed in detail with respect to the population and area of the city, where there is a decrease less than $1 \%$ in the coverage of the isochrone curves, so there is no outstanding impact on the mobility of the city, but noticeable in the studied area.

Regarding the gradient of savings, comparison of the scenarios in the intrgral accessibility, the result can be seen in Figure 7 where the greatest differences are seen in the gastronomic zone and its surroundings, with intervals between $106.69 \%$ and $-7.5 \%$ due greatly to the nodes used to calculate the integral accessibility located in that area and the travel times are minimum for both scenarios, so a restriction in road direction will produce large differences
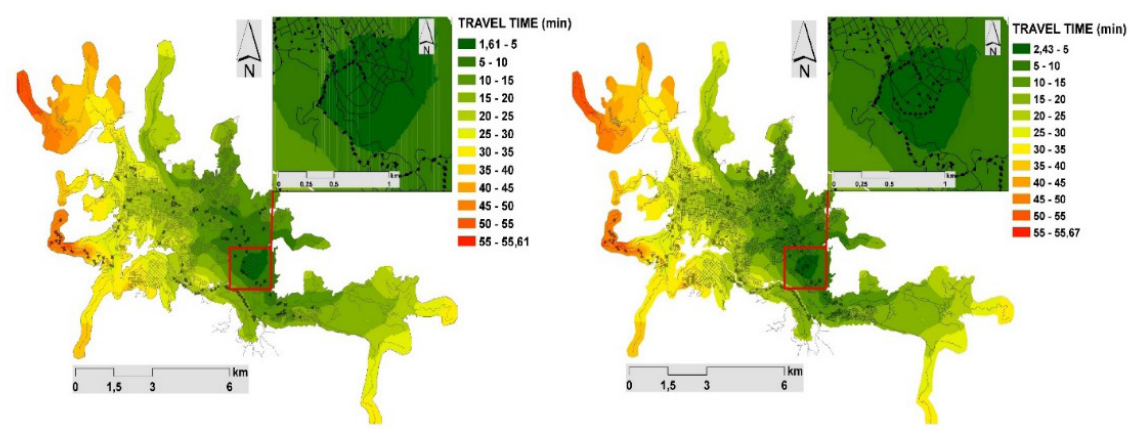

Figure 6. Isochrones curves, Integral accessibility.

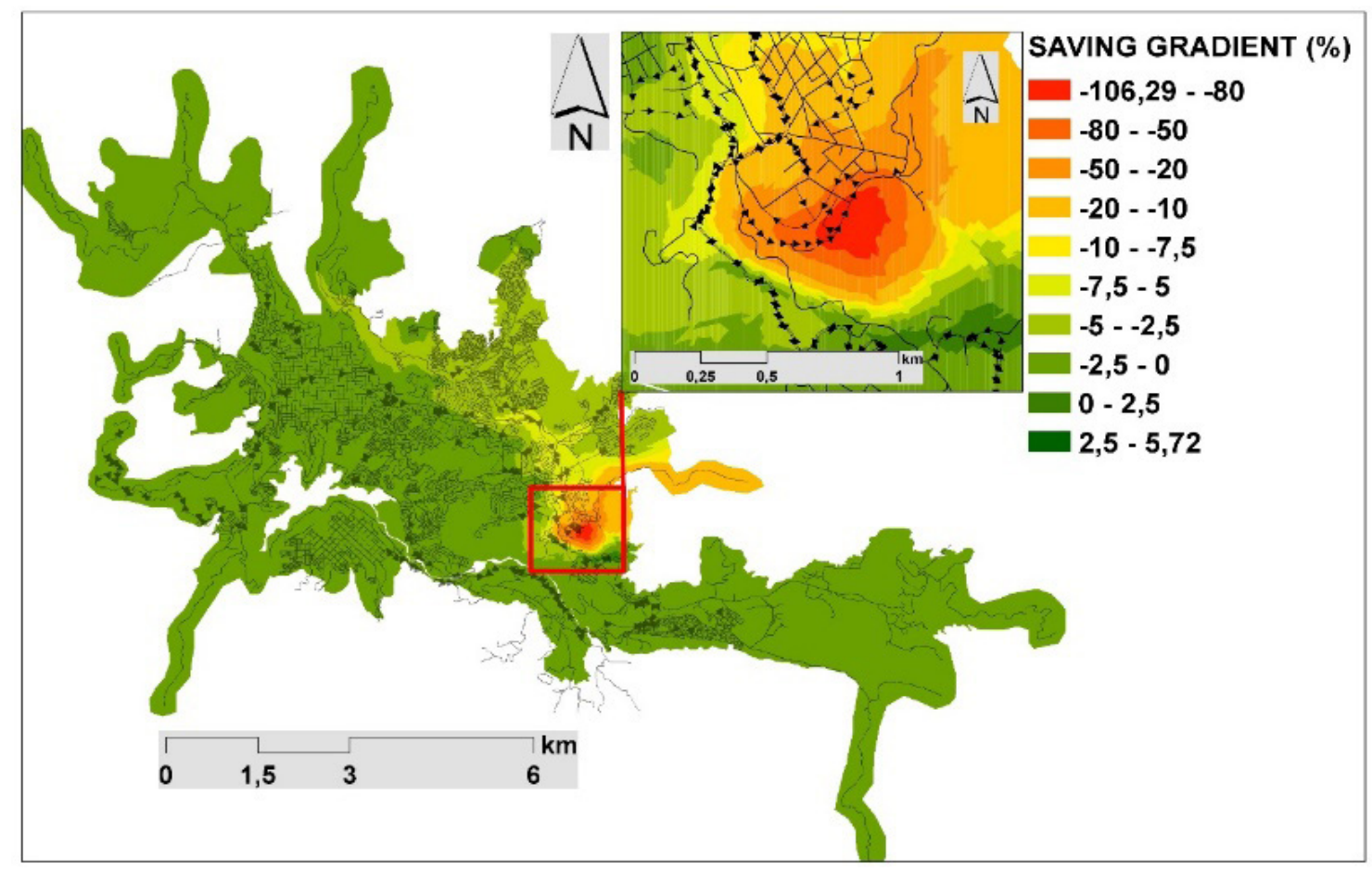

Figure 7. Saving gradient, integral accessibility. 
Table 3. Area and inhabitants coverage per isochrones curve, integral accessibility

\begin{tabular}{|c|c|c|c|c|c|c|}
\hline \multicolumn{7}{|c|}{ Global Average Accesibility - Base Situation } \\
\hline $\begin{array}{l}\text { Isochrones } \\
\text { Curve }\end{array}$ & Area & Inhabitants & $\%$ Area & \% Inhabitants & $\begin{array}{l}\% \text { Accumulated } \\
\text { Area }\end{array}$ & $\begin{array}{l}\text { \% Accumulated } \\
\text { Inhabitants }\end{array}$ \\
\hline $1,61-5$ & 76,31 & 5879,38 & $1,30 \%$ & $1,40 \%$ & $1,30 \%$ & $1,40 \%$ \\
\hline $5-10$ & 458,00 & 25323,88 & $7,81 \%$ & $6,03 \%$ & $9,11 \%$ & $7,43 \%$ \\
\hline $10-15$ & 920,15 & 109862,17 & $15,69 \%$ & $26,18 \%$ & $24,81 \%$ & $33,61 \%$ \\
\hline $15-20$ & 1112,21 & 76025,26 & $18,97 \%$ & $18,11 \%$ & $43,77 \%$ & $51,73 \%$ \\
\hline $20-25$ & 1037,67 & 96784,95 & $17,70 \%$ & $23,06 \%$ & $61,47 \%$ & $74,79 \%$ \\
\hline $25-30$ & 818,56 & 77526,00 & $13,96 \%$ & $18,47 \%$ & $75,43 \%$ & $93,26 \%$ \\
\hline $30-35$ & 628,45 & 23524,04 & $10,72 \%$ & $5,61 \%$ & $86,15 \%$ & $98,86 \%$ \\
\hline $35-40$ & 355,29 & 2072,83 & $6,06 \%$ & $0,49 \%$ & $92,21 \%$ & $99,36 \%$ \\
\hline $40-45$ & 207,34 & 2155,72 & $3,54 \%$ & $0,51 \%$ & $95,74 \%$ & $99,87 \%$ \\
\hline $45-50$ & 163,71 & 536,58 & $2,79 \%$ & $0,13 \%$ & $98,54 \%$ & $100,00 \%$ \\
\hline $50-55$ & 79,95 & 0,00 & $1,36 \%$ & $0,00 \%$ & $99,90 \%$ & $100,00 \%$ \\
\hline $55-55,61$ & 5,93 & 0,00 & $0,10 \%$ & $0,00 \%$ & $100,00 \%$ & $100,00 \%$ \\
\hline Totally & 5863,58 & 419690,81 & $100 \%$ & $100 \%$ & & \\
\hline \multicolumn{7}{|c|}{ Global Average Accesibility - Future Situation } \\
\hline $\begin{array}{l}\text { Isochrones } \\
\text { Curve }\end{array}$ & Area & Inhabitants & $\%$ Area & $\%$ Inhabitants & $\begin{array}{l}\% \text { Accumulated } \\
\text { Area }\end{array}$ & $\begin{array}{l}\text { \% Accumulated } \\
\text { Inhabitants }\end{array}$ \\
\hline $2,43-5$ & 53,81 & 4813,33 & $0,92 \%$ & $1,15 \%$ & $0,92 \%$ & $1,15 \%$ \\
\hline $5-10$ & 437,20 & 22267,70 & $7,46 \%$ & $5,31 \%$ & $8,37 \%$ & $6,45 \%$ \\
\hline $10-15$ & 911,29 & 107918,04 & $15,54 \%$ & $25,71 \%$ & $23,92 \%$ & $32,17 \%$ \\
\hline $15-20$ & 1128,50 & 79955,44 & $19,25 \%$ & $19,05 \%$ & $43,16 \%$ & $51,22 \%$ \\
\hline $20-25$ & 1049,01 & 96693,85 & $17,89 \%$ & $23,04 \%$ & $61,05 \%$ & $74,26 \%$ \\
\hline $25-30$ & 833,49 & 79169,70 & $14,21 \%$ & $18,86 \%$ & $75,27 \%$ & $93,12 \%$ \\
\hline $30-35$ & 631,06 & 24087,98 & $10,76 \%$ & $5,74 \%$ & $86,03 \%$ & $98,86 \%$ \\
\hline $35-40$ & 358,42 & 1991,59 & $6,11 \%$ & $0,47 \%$ & $92,14 \%$ & $99,33 \%$ \\
\hline $40-45$ & 209,44 & 2234,94 & $3,57 \%$ & $0,53 \%$ & $95,71 \%$ & $99,87 \%$ \\
\hline $45-50$ & 163,59 & 560,11 & $2,79 \%$ & $0,13 \%$ & $98,50 \%$ & $100,00 \%$ \\
\hline $50-55$ & 81,14 & 0,00 & $1,38 \%$ & $0,00 \%$ & $99,89 \%$ & $100,00 \%$ \\
\hline $55-55,67$ & 6,64 & 0,00 & $0,11 \%$ & $0,00 \%$ & $100,00 \%$ & $100,00 \%$ \\
\hline Totally & 5863,58 & 419692,69 & $100 \%$ & $100 \%$ & & \\
\hline
\end{tabular}

in travel times and in the future scenario should be longer routes to travel within Zone G. likewise, as the routes are longer to reach the studied nodes in Zone G, the savings gradients decrease in much of the city to percentages between $-2.5 \%$ and $0 \%$, isochronous curve that has greater coverage. In the north-east of the city and north of the studied area, differences between $-10 \%$ and $-2.5 \%$ are perceived, due to the proximity to Zone G and the provision of changes direction contra clockwise.
On the other hand, Table 4 shows the coverage of the isochronous gradient savings curves in relation to the population and area of the city where a percentage of $3.6 \%$ of population (15 090 inhabitants) and 5.85\% (343 ha) are found with differences between $-106.28 \%$ and $-5 \%$. Furthermore, $71.09 \%$ of people find differences between $-2.5 \%$ and $0 \%$, while the percentage in area is $81.91 \%$ for the same interval. In addition, Figure 8 shows the routes where it is proposed to complement the boulevard built in 2015 . 


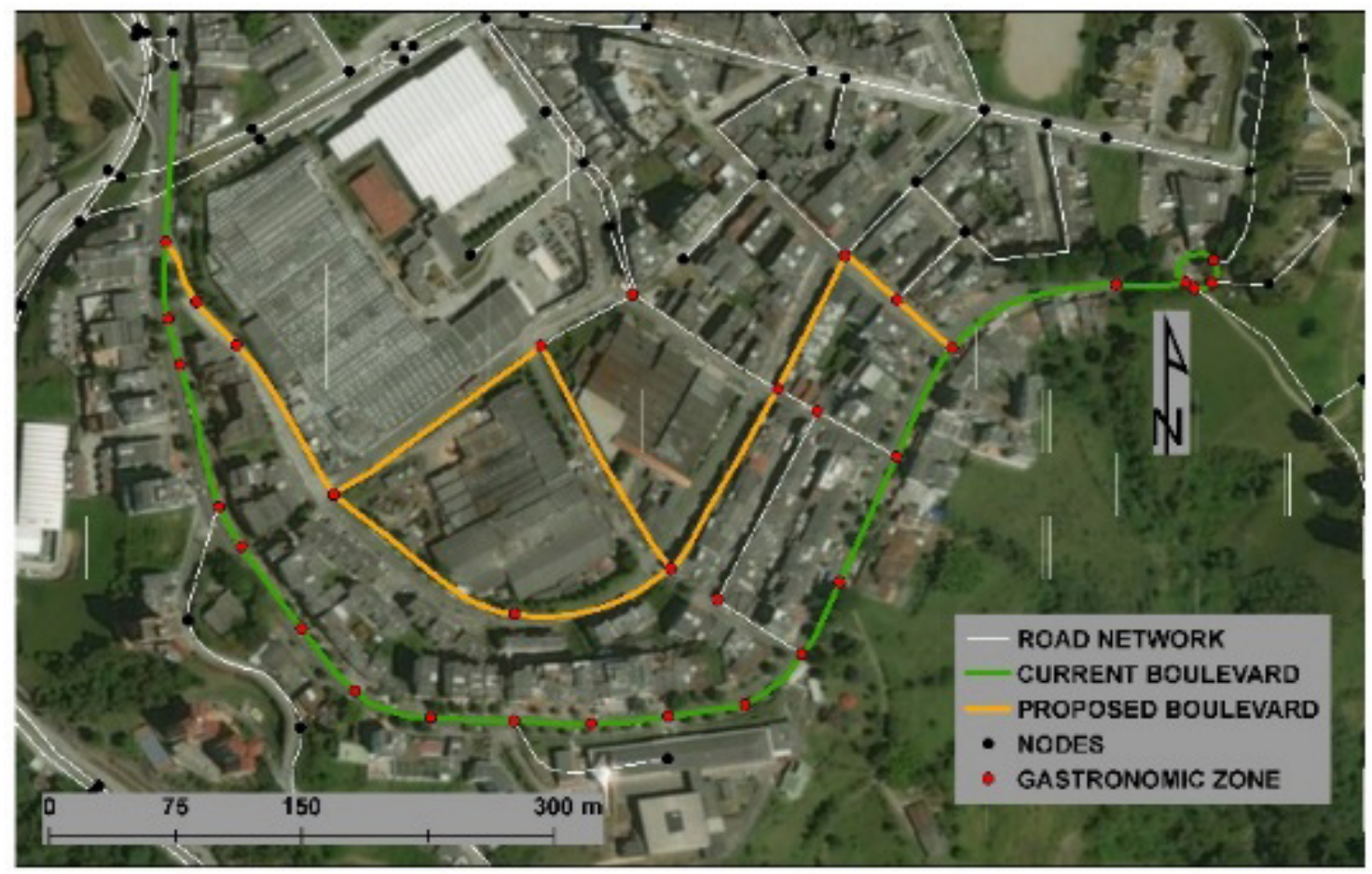

Figure 8. Proposed boulevard.

Table 4. Area and inhabitants coverage per isochrones curve, saving gradient between integral accessibility on analyzed scenarios

\begin{tabular}{|l|l|l|l|l|}
\hline \multicolumn{2}{|l|}{ Saving Gradient - Gastronomic Zone Re Direction Scenario } \\
\hline $\begin{array}{l}\text { Isochronos } \\
\text { Curve }\end{array}$ & Area & Inhabitants & \% Area & $\begin{array}{l}\% \\
\text { Inhabitants }\end{array}$ \\
\hline $\begin{array}{l}-\mathbf{1 0 6 , 2 9}- \\
-\mathbf{8 0}\end{array}$ & 5,127 & 293,592 & $0,0874 \%$ & $0,0700 \%$ \\
\hline $\mathbf{- 8 0}-\mathbf{- 5 0}$ & 9,147 & 599,779 & $0,1560 \%$ & $0,1429 \%$ \\
\hline $\mathbf{- 5 0}-\mathbf{2 0}$ & 28,132 & 2326,207 & $0,4798 \%$ & $0,5543 \%$ \\
\hline $\mathbf{- 2 0}-\mathbf{- 1 0}$ & 142,862 & 3801,180 & $2,4364 \%$ & $0,9057 \%$ \\
\hline $\mathbf{- 1 0}-\mathbf{- 7 , 5}$ & 34,300 & 1854,510 & $0,5850 \%$ & $0,4419 \%$ \\
\hline $\mathbf{- 7 , 5}-\mathbf{- 5}$ & 123,226 & 6215,242 & $2,1015 \%$ & $1,4810 \%$ \\
\hline $\mathbf{- 5}-\mathbf{- 2 , 5}$ & 711,779 & 106007,164 & $12,1386 \%$ & $25,2593 \%$ \\
\hline $\mathbf{- 2 , 5}-\mathbf{0}$ & 4802,808 & 298362,859 & $81,9069 \%$ & $71,0935 \%$ \\
\hline $\mathbf{0}-\mathbf{2 , 5}$ & 6,366 & 221,462 & $0,1086 \%$ & $0,0528 \%$ \\
\hline Totally & 5863,748 & 419681,995 & $100,0 \%$ & $100,0 \%$ \\
\hline
\end{tabular}

\section{Conclusions}

In terms of global mean accessibility, the impacts generated by the road re-direction in the gastronomic zone are minimal in terms of average travel time, while in the integral accessibility to Zone G, appreciable differences are generated in the studied area and the northern part of the city. These changes of direction can increase travel times in a large part of the city, but in very small percentages, in both measures, because vehicles must make longer routes to reach the same nodes given the unifications in Zone G. These restrictions can generate a decrease in the use of private vehicles to go to Zone G, generating an increase in people accessing it by public transport or the decision to park the vehicle in its surroundings and move within it walking.

Parallel to the unification of these roads in the gastronomic zone, an analysis of parking of vehicles on this area and its surroundings must be made in order to reduce parking on the road and promote parking in authorized areas in the surroundings, generating that main mode of transport within the area would be walking. Since they belong to the road unification proposal and seek to improve the conditions for pedestrian traffic by extending platforms and lighting and offer additional spaces for the parking of vehicles.

In addition, for future research, the analysis of this type of decision should be complemented by micro traffic simulations that explain the current and future behavior of the area of study. As a final conclusion, this type of 
measure is beneficial in terms of mobility because it contributes to the ordering of daily traffic. However, this type of action must go hand in hand with urban and organizational actions in order to promote sustainable means of transport in the area such as public transport and walking in order to reduce the problems of private vehicle parking and then make the Zona G, in Manizales a priority place for the visit of tourists and residents of the city.

\section{Aknowledgement}

The authors would like to thank the research group on sustainable mobility of the National University of Colombia at Manizales.

\section{References}

1. Bahls ÁA, Krause RW, Farias FdeS. Planejamento gastronômico em destinos turísticos: Uma Comparação entre o Panorama Nacional e o Estrangeiro. Revista Rosa Dos Ventos - Turismo e Hospitalidade. 2015; 7(2):223-41.

2. Manizales ya tiene zona donde la gastronomia es protagonista: Paseo de Milán-Zona G. [Internet]. [cited 2015 Dec 14]. Available from: http://www.ciudadregion.com/ manizales/manizales-ya-tiene-zona-donde-gastronomiaprotagonista-paseo-milan-g_1450093981.

3. El barrio Milán de Manizales también tendrá bulevar. [Internet]. [cited 2015 Apr 04]. Available from:http://www. lapatria.com/manizales/el-barrio-milan-de-manizalestambien-tendra-bulevar-179033.

4. A partir del 5 de Junio habrá unificación vial en Milán. [Internet]. [cited 2018 May 24]. Available from:http://www. saladeprensamanizales.com/noticia/7616.

5. Plan piloto de unificación vial para la zona G de Milán. [Internet]. [cited 2018 May 27]. Available from:http://www. saladeprensamanizales.com/noticia/7661.

6. Geurs KT, Ritsema van Eck JR. Accessibility measures: Review and applications. Evaluation of accessibility impacts of land-use transportation scenarios, and related social and economic impact. RIVM rapport 408505006; 2001. p. $1-265$.

7. Hansen WG. How accessibility shapes land use. Journal of the American Institute of Planners. 1959; 25(2):73-6. https://doi.org/10.1080/01944365908978307

8. Pirie GH. Measuring accessibility: A review and proposal. Environment and Planning A. 1979; 11(3):299-312. https://doi.org/10.1068/a110299

9. Olsson M. Functional regions in gravity models and accessibility measures. Moravian Geographical Reports. 2016; 24(2):60-70. https://doi.org/10.1515/mgr-2016-0011
10. Xiao Y, Sarkar C, Webster C, Chiaradia A, Lu Y. Street network accessibility-based methodology for appraisal of land use master plans: An empirical case study of Wuhan. China. Land Use Policy. 2017 Sep; 69:193-203. https://doi. org/10.1016/j.landusepol.2017.09.013

11. Beria P, Debernardi A, Ferrara E. Measuring the longdistance accessibility of Italian cities. Journal of Transport Geography. 2017; 62:66-79. https://doi.org/10.1016/j. jtrangeo.2017.05.006

12. Nassir N, Hickman M, Malekzadeh A, Irannezhad E. A utility-based travel impedance measure for public transit network accessibility. Transportation Research Part A: Policy and Practice. 2016; 88:26-39. https://doi. org/10.1016/j.tra.2016.03.007

13. Ingram DR. The concept of accessibility: A search for an operational form. Regional Studies. 1971; 5(2):101-7. https://doi.org/10.1080/09595237100185131

14. Escobar DA, Cardona S, Moncada CA. Urban territorial accessibility through road infrastructure works and betterment levy area. Research Journal of Applied Sciences. 2018; 13(7):431-8.

15. Escobar DA, García F, Tolosa R. Análisis de accesibilidad territorial a nivel regional. Universidad Nacional de Colombia. Facultad de Ingeniería y Arquitectura, Manizales; 2013.

16. Perilla DJ, Escobar DA, Cardona S. New transportation infrastructure impact in terms of global average access Intersection "La Carola" Manizales (Colombia) case study. Contemporary Engineering Sciences. 2018; 11(5):215-27. https://doi.org/10.12988/ces.2018.812

17. Moncada CA, Cardona S, Escobar DA. Saving travel time as an urban planning instrument. case study: Manizales, Colombia. Modern Applied Science. 2018; 12(6):44-57. https://doi.org/10.5539/mas.v12n6p44

18. Barco A, Escobar DA, Moncada CA. Road redirection analysis. Case study: Araucarias Avenue, Manizales, Colombia. Contemporary Engineering Sciences. 2018; 11(32):1559-69. https://doi.org/10.12988/ces.2018.84154

19. Escobar DA, Duque JP, Salas A. Accesibilidad como herramienta de planeación urbana. Caso de estudio: Redireccionamiento vial en Riosucio (Caldas - Colombia). Avances Investigación En Ingeniería. 2015; 11(2):9-8. https://doi.org/10.18041/1794-4953/avances.2.231

20. Mello A, Portugal L. Um procedimento baseado na acessibilidade para a concepção de planos estratégicos de mobilidade urbana: O caso do Brasil. EURE (Santiago). 2017; 43(128):99-126. https://doi.org/10.4067/S025071612017000100005

21. Farber S, Fu L. Dynamic public transit accessibility using travel time cubes: Comparing the effects of infrastructure (dis)investments over time. Computers, Environment and 
Urban Systems. 2017; 62:30-40. https://doi.org/10.1016/j. compenvurbsys.2016.10.005

22. Grengs J. Nonwork accessibility as a social equity indicator. International Journal of Sustainable Transportation. 2014; 9(1):1-14. https://doi.org/10.1080/15568318.2012.7 19582

23. Allen WB, Liu D, Singer S. Accesibility measures of U.S. metropolitan areas. Transportation Research Part B. 1993; 27(6):439-49. https://doi.org/10.1016/01912615(93)90016-4

24. Escobar DA, Cardona, S, Moncada, CA. Global mean accessibility in metropolitan areas. Case study: Chinchiná, Colombia. Indian Journal of Science and Technology. 2018; 11(21):1-10. https://doi.org/10.17485/ijst/2018/ v11i21/123113

25. Higgs G, Jones S, Langford M, Heley J. Assessing the impacts of changing public service provision on geographical accessibility: An examination of public library provision in Pembrokeshire, South Wales. Environment and Planning C: Politics and Space. 2017; 36(3):548-68.

26. Xiao X, Aultman-Hall L, Manning R, Voigt B. The impact of spatial accessibility and perceived barriers on visitation to the US national park system. Journal of Transport Geography. 2018 Apr; 68:205-14. https:/doi. org/10.1016/j.jtrangeo.2018.03.012
27. Kozyrev VP. Graph theory. Journal of Soviet Mathematics. 1974; 2(5):489-519. https://doi.org/10.1007/BF01085015

28. Escobar DA, Garcia F. Diagnostico de la Movilidad Urbana de Manizales.1th Edition. Universidad Nacional de Colombia sede Manizales; 2012.

29. Proyecciones de población total por sexo y grupos de edad de 0 hasta 80 y más a-os (2005 - 2020). [Internet]. [cited 2018 Apr 10]. Available from:https://www.dane.gov.co/ index.php/estadisticas-por-tema/demografia-y-poblacion/proyecciones-de-poblacion.

30. Dijkstra EW. A note on two problems in connexion with graphs. Numerical Mathematics. 1959; 1(1):269-71. https://doi.org/10.1007/BF01386390

31. Zuluaga JD, Escobar DA. Geomarketing analysis for shopping malls in Manizales (Colombia). Accessibility approach methodology. Revista Espacios. 2017; 38(21):1-20.

32. Escobar DA, Montoya JA, Moncada, CA. Accessibility analysis towards urban ecoparks as a measure of integral environmental planning - case study: Manizales, Colombia. Indian Journal of Science and Technology. 2018; 11(21). https://doi.org/10.17485/ijst/2018/v11i21/122476

33. Simpson TW, Mauery TM, Korte J \& Mistree F. Kriging models for global approximation in simulation-based multidisciplinary design optimization. AIAA Journal. 2001; 39(12):2233-41. https://doi.org/10.2514/2.1234 